\section{Stability of Expression and Concentration of Ascorbic Acid in North American Potato Germplasm}

\author{
Stephen L. Love ${ }^{1}$ and Thomas Salaiz ${ }^{2}$ \\ University of Idaho, Aberdeen R\&E Center, Aberdeen, ID 83210
}

Bahman Shafii ${ }^{3}$ and William J. Price ${ }^{4}$

University of Idaho, Statistical Programs, P.O. Box 442337, Moscow, ID 83844

\author{
Alvin R. Mosley ${ }^{5}$ \\ Oregon State University, Department of Crop and Soil Sciences, Corvallis, \\ OR 97331
}

\section{Robert E. Thornton ${ }^{5}$ Architecture, Pullman, WA 99164 \\ Additional index words. Solanum tuberosum, vitamin C, biplot analysis}

Washington State University, Department of Horticulture and Landscape

\begin{abstract}
Ascorbic acid (vitamin C) is an essential nutrient in the human diet and potatoes are a valuable source. As a first step in breeding for potatoes (Solanum tuberosum L.) with higher levels of ascorbic acid, 75 clones from 12 North American potato-breeding programs were evaluated for concentration, and 10 of those for stability of expression. Trials were grown in Idaho, Oregon, and Washington in 1999 and 2000, tubers sampled, and ascorbic acid quantified. There were significant differences among clones and clone by environment interaction was also significant. Concentration of ascorbic acid of the clones was continuously distributed over a range of 11.5 to $29.8 \mathrm{mg} / 100 \mathrm{~g}$. A subgroup of 10 clones was analyzed using an additive main effects and multiplicative interaction (AMMI) model, to diagnose interaction patterns and measure clone stability. The first two principal component axes accounted for over $80 \%$ of the variability. Bi-plot analysis showed 'Ranger Russet' to be highly unstable across the environments tested. A plot of Tai's stability statistics found six of the $\mathbf{1 0}$ clones to be stable for ascorbic acid expression. Appropriate evaluation methods for ascorbic acid concentration must involve multi-year testing.
\end{abstract}

Ascorbic acid is important in the human diet as an essential vitamin and as an antioxidant. Potatoes are a valuable source of ascorbic acid for people living in the United States. A single148-g uncooked potato provides $45 \%$

Received for publication 17 June 2002. Accepted for publication 10 Feb. 2003. This paper is manuscript number 02718 of the Idaho Agricultural Experiment Station series. Financial support for this research came in part from USDA/CSREES grant number 99-341417685 . We gratefully acknowledge the support of the technical staff at the Aberdeen R\&ECenter, including Edith Isaak, Peggy Bain, and Scott Cordon. We also acknowledge Paul Andersen for plot management, and the following for providing seed of clones: David Holm, Colorado State Univ.; Joseph Pavek and Dennis Corsini, USDA/ARS, Aberdeen, Idaho; the late Alvin Reeves, Univ. of Maine; Kathleen Haynes, USDA/ ARS, Beltsville, Md.; David Douches, Michigan State Univ.; Christian Thill, Univ.of Minnesota; Richard Tarn, Agriculture Canada, Fredericton, N.B.; Robert Plaisted, Cornell Univ.; Rich Novy, North Dakota State Univ.; Creighton Miller, Jr., Texas A\&M Univ.; Horia Groza and Jiming Jiang, Univ. of Wisconsin; and Robert Hanneman, USDA/ARS, Madison, Wis.

${ }^{1}$ Research Professor. To whom reprint requests should be sent. Phone: (208) 397-4181; e-mail: slove@uidaho.edu.

${ }^{2}$ Support Scientist.

${ }^{3}$ Professor and Director of Statistical Programs.

${ }^{4}$ Statistician.

${ }^{5}$ Professor.
$33 \%$ for mashed potatoes, $53 \%$ for blanched preformed patties, and $12 \%$ to $40 \%$ for reconstituted dehydrated products (Artz et al., 1983; Augustin et al., 1979a, 1979b; Sumner et al., 1983; Wang et al., 1992). Retention in potato chips was reported to be $\approx 30 \%$, although the actual concentration in the chips is often higher than in the raw potato because of water loss during processing (Wills, 1987).

In spite of cooking losses, potatoes are an important source of ascorbic acid. Storey and Davies (1992) cited studies showing that from $15 \%$ to over $30 \%$ of the ascorbic acid intake among people in the United Kingdom comes from potatoes. Wills (1987) determined that $25 \%$ of ascorbic acid intake in Australia is from potatoes.

Given the potential health benefits of ascorbic acid and the importance of potatoes in supplying this nutrient, any increase in ascorbic acid concentration in potatoes could potentially provide population-wide health benefits. This is especially true in many developing countries, where potatoes make up a large part of a subsistence diet. Studies documenting the genetic potential for increase, or defining the theoretical upper limit of ascorbic acid, in potatoes are lacking. However, several authors have reported differences in ascorbic acid concentration among commonly used potato cultivars (Augustin et al., 1978; Workman and Holm, 1984; Kemp and Kemp, 1982; Mullin et al., 1991). Augustin et al. (1978) reported ascorbic acid concentration among eight cultivars ranging from 7.9 to $36.1 \mathrm{mg} /$ $100 \mathrm{~g}$ fresh weight (FW) basis. This provides some evidence for genetic variability and the associated possibility of breeding for higher concentrations of ascorbic acid.

Research is needed to document the potential maximum expression, the stability among production environments, and/or the genetics of expression of ascorbic acid concentration in potatoes. The study described here is the first of several to delineate the genetic characteristics of ascorbic acid concentration in potatoes, including the range of ascorbic acid concentration within North American breeding germplasm and the phenotypic stability of expression across production environments.

\section{Materials and Methods}

Requests for parental breeding stocks were made to all major public breeding programs in North America with the intent of sampling the most commonly used genetic resources. Each breeder was asked for predominantly utilized parental clones (commonly used term in potatoes for both released cultivars and breeding germplasm) from their program. Respondents included breeders in Colorado (submitted 5 clones for evaluation), Idaho [U.S. Dept. of Agriculture, Agricutural Research Service (USDA/ARS)] (6), Maine (5), Maryland (USDA/ARS) (5), Michigan (5), Minnesota (6), New Brunswick (6), New York (5), North Dakota (7), Texas (2), and Wisconsin (5). Fourteen additional clones were obtained from the USDA/ARS Germplasm Enhancement program in Wisconsin. Also, four clones, 
known to be either high or low in ascorbic acid, based on preliminary observations, were obtained from the Idaho, and included as controls. All clones included in the study, except those from the Wisconsin Germplasm Enhancement program were tetraploid, derived from $S$. tuberosum background, and adapted to northern temperate production areas. The clones from the Enhancement program were from a collection made up of individuals derived from crosses with wild species (one to three generations removed from the species), with unconfirmed ploidy level and variable adaptation. A total of 75 clones were evaluated.

Tubers used for ascorbic acid measurements were produced in trials grown at Aberdeen, Idaho; Corvallis, Ore.; and Othello, Wash., in 1999 and 2000. Each trial within a site consisted of two replications of five hills, arranged as a randomized complete block. Cultural practices at each location were typical of those used by local producers.

Five tubers from each plot were harvested and shipped to the Aberdeen R\&E Center for measurement of ascorbic acid. Within a month of harvest, five whole tubers (skin intact) from each plot were diced, frozen in liquid nitrogen, and lyophilized. The resulting freezedried tissue was ground through a 40-mesh screen and analyzed using the AOAC (1984) microflourometric method. Ascorbic acid was extracted from the freeze-dried tissue using a solution of metaphosphoric and acetic acids, followed by addition of sodium acetate and O-phenylene diamine, and measurement of the subsequence fluorescence in a Turner flourometer. Final values were determined using a standard curve.

Germplasm screening. Ascorbic acid concentration for all 75 clones was initially analyzed across all years and locations (environments) using analysis of variance (ANOVA). Each location/year was considered to be a separate environment and both environment and genotypes were considered to be random effects. Estimated clonal means from the analysis were separated using Fisher's least significant difference (LSD) method.

$G \times E$ analysis. A subset of the data, consisting of all locations and years for 10 clones, was subsequently selected to explore the genotype $\times$ environment $(\mathrm{G} \times \mathrm{E})$ interaction and to provide stability assessments. For ease of interpretation and simplification of pattern detection, only 10 clones were utilized in this part of the analysis. The 10 clones chosen included commonly produced cultivars, plus the low and high concentration ascorbic acid controls. These last four clones were included to ensure a wide range of ascorbic acid content for this part of the analysis. The clones used in the stability analysis were 'Chipeta' (high control), A85331-1 (high control), A8792-11 (low control), A79141-3 (low control), and six common cultivars, 'Cherry Red', 'Ivory Crisp', 'Krantz', 'Ranger Russet', 'Snowden', and 'Yukon Gold'. Following the procedure described by Shafii and Price (1998), the AMMI model used to analyze the $\mathrm{G} \times \mathrm{E}$ interaction was as follows:

$$
y_{i j}=\mu+g_{i}+l_{j}+\delta_{i j}
$$

where:

$$
\begin{aligned}
y_{i j}= & \text { observed response (ascorbic acid } \\
& \text { concentration) value of clone (genotype) } \\
& \mathrm{i} \text { in environment } \mathrm{j} \\
\mu \quad= & \text { grand mean } \\
g_{i}= & \text { genotype effect } \mathrm{i}, \mathrm{i}=1 \ldots \mathrm{k} \\
l_{j}= & \text { environment effect } \mathrm{j}, \mathrm{j}=1 \ldots \mathrm{n} \\
\delta_{i j}= & \text { interaction }=\mu_{\mathrm{ij}}-\mu_{\mathrm{i} .}-\mu_{\mathrm{i} .}+\mu .
\end{aligned}
$$

\begin{tabular}{|c|c|c|c|c|c|}
\hline Cultivar & $\begin{array}{c}\text { Concn } \\
(\mathrm{mg} / 100 \mathrm{~g})\end{array}$ & $\begin{array}{c}\text { Contributing } \\
\text { program }^{y}\end{array}$ & Cultivar & $\begin{array}{c}\text { Concn } \\
(\mathrm{mg} / 100 \mathrm{~g})\end{array}$ & $\begin{array}{c}\text { Contributing } \\
\text { program }\end{array}$ \\
\hline ND4027-4 & 29.8 & ND & ND2225-1R & 19.6 & ND \\
\hline Ranger Russet & 29.4 & ID & Red Companion & 19.5 & WI \\
\hline Yukon Gold & 29.3 & MI & Durango Red & 19.2 & $\mathrm{CO}$ \\
\hline Russet Nugget & 28.7 & TX & MN17922 & 19.1 & MN \\
\hline A85331-16 (control) & 28.6 & ID & EB8109-1 & 19.0 & ME \\
\hline Silverton Russet & 27.0 & $\mathrm{CO}$ & Snowden & 18.8 & WI \\
\hline W1313 & 27.0 & WI & WH10392 & 18.8 & WIG \\
\hline MN17993 & 26.9 & MN & NY115 & 18.5 & NY \\
\hline Avon & 26.5 & MD & BO607-33 & 18.4 & MD \\
\hline AC $87079-3$ & 26.3 & $\mathrm{CO}$ & NY121 & 17.7 & NY \\
\hline MN18142 & 26.3 & MN & Dakota Rose & 17.6 & ND \\
\hline WH1327 & 26.2 & WIG & WH10411 & 17.4 & WIG \\
\hline Gem Russet & 26.1 & ID & NY123 & 17.0 & NY \\
\hline Shepody & 25.5 & NB & USDA41956 & 16.9 & MD \\
\hline F65089 & 25.5 & NB & W1099Russ & 16.8 & WI \\
\hline BO692-4 & 25.4 & MD & Spartan Pearl & 16.6 & MI \\
\hline Chipeta (control) & 25.3 & ID & W1242 & 16.6 & WI \\
\hline NY112 & 25.3 & NY & NorDonna & 16.5 & ND \\
\hline CO89036-10 & 25.2 & $\mathrm{CO}$ & WH10233 & 16.4 & WIG \\
\hline Krantz & 24.2 & $\mathrm{TX}$ & NDA2031-2 & 16.3 & ID \\
\hline VWB222-12 & 24.0 & ME & F81108 & 15.9 & NB \\
\hline Jacqueline Lee & 23.5 & MI & F59203 & 15.8 & NB \\
\hline A86102-6 & 23.5 & ID & WH10276 & 15.7 & WIG \\
\hline AF522-5 & 23.4 & ME & WH10214 & 15.7 & WIG \\
\hline F73068 & 23.4 & NB & B1065-61 & 15.6 & MD \\
\hline ND5256-7R & 23.4 & ND & S440 & 15.3 & MN \\
\hline Eva' & 23.0 & NY & WH10213 & 15.3 & WIG \\
\hline MN18714 & 22.9 & MN & MSG227-2 & 15.0 & MI \\
\hline ND2470-27 & 22.3 & ND & Cherry Red & 14.9 & $\mathrm{CO}$ \\
\hline MSBO76-2 & 22.1 & MI & WH10438 & 14.5 & WIG \\
\hline WH1325 & 22.1 & WIG & WH1302 & 14.5 & WIG \\
\hline WH1321 & 21.8 & WIG & CS7232-4 & 14.3 & ME \\
\hline Dakota Pearl & 21.6 & ND & WH10470 & 13.9 & WIG \\
\hline Ivory Crisp & 21.4 & ID & S438 & 13.7 & MN \\
\hline AF303-5 & 21.0 & ME & A79141-3 (control) & 13.3 & ID \\
\hline F66041 & 20.7 & NB & WH10469 & 13.0 & WIG \\
\hline WH10234 & 20.1 & WIG & A8792-11 (control) & 11.5 & ID \\
\hline A84118-3 & 20.0 & ID & $\mathrm{LSD}_{(0.05)}$ & 2.0 & \\
\hline
\end{tabular}

Table 1. Analysis of variance results for tuber ascorbic acid concentration of 75 clones grown for 2 years in Idaho, Oregon, and Washington.

\begin{tabular}{lcrrr}
\hline Source & $\begin{array}{c}\text { Degrees of } \\
\text { freedom }\end{array}$ & $\begin{array}{c}\text { Sums of } \\
\text { squares }\end{array}$ & $\begin{array}{r}\text { Mean } \\
\text { square }\end{array}$ & \multicolumn{1}{c}{ F value } \\
\hline Environment & 5 & 14,620 & 2924.09 & $462.08^{* * * *}$ \\
Rep(Environment) & 5 & 603 & 120.62 & $19.06^{* * * *}$ \\
Clone & 74 & 20,202 & 273.01 & $43.14^{* * * *}$ \\
Env. $\times$ Genotype & 367 & 5,394 & 14.70 & $2.32^{* * *}$ \\
Error & 436 & 2,759 & 6.33 & \\
Total & 888 & 43,662 & & \\
${ }^{* * * *}$ Significant at $P=0.001$. & & &
\end{tabular}

Table 2. Average ascorbic acid concentration in tubers of 75 clones collected from North American potato breeding programs. ${ }^{2}$

${ }^{2}$ Potato clones were grown at Aberdeen, Idaho; Corvallis, Ore.; and Othello, Wash., in 1999 and 2000. ${ }^{y}$ Breeding programs contributing germplasm: $\mathrm{CO}=$ Colorado State Univ.; $\mathrm{ID}=$ Univ. of Idaho and the USDA/ARS; MD = USDA/ARS at Beltsville, Md.; ME = Univ. of Maine; MI = Michigan State Univ.; MN = Univ. of Minnesota; NB = Agriculture Canada at Fredericton, New Brunswick; ND = North Dakota State Univ.; NY = Cornell Univ. TX = Texas A\&M Univ.; WI = Univ. of Wisconsin breeding program; $\mathrm{WIG}=\mathrm{USDA} / \mathrm{ARS}$ Germplasm Enhancement Program at the Univ. of Wisconsin. 
Table 3. Ascorbic acid concentration of clones, averaged for each contributing breeding program.

\begin{tabular}{lcc}
\hline Clone & $\begin{array}{c}\text { Range of concn } \\
\text { concn }(\mathrm{mg} / 100 \mathrm{~g})\end{array}$ & Clone means \\
\hline Colorado & 22.5 & $14.9-27.0$ \\
Idaho & 21.5 & $16.3-29.4$ \\
Maine & 20.4 & $14.3-24.0$ \\
Maryland & 20.6 & $15.6-26.5$ \\
Michigan & 21.3 & $15.0-29.3$ \\
Minnesota & 20.7 & $13.7-26.9$ \\
New Brunswick & 21.1 & $15.8-25.5$ \\
New York & 20.3 & $17.0-25.3$ \\
North Dakota & 21.5 & $16.5-29-8$ \\
Texas & 26.4 & $24.2-28.7$ \\
Wisconsin (Breeding) & 19.7 & $16.6-27.0$ \\
Wisconsin (Germplasm) & 17.2 & $13.0-26.2$ \\
Control clones & 19.9 & $11.5-28.6$ \\
\hline
\end{tabular}

Table 4. Analysis of variance results for tuber ascorbic acid concentration of 10 selected potato clones grown in Idaho, Oregon, and Washington in 1999 and 2000 and used in the stability analysis.

\begin{tabular}{lcccrc}
\hline Source & $\begin{array}{c}\text { Degrees of } \\
\text { freedom }\end{array}$ & $\begin{array}{c}\text { Sums of } \\
\text { squares }\end{array}$ & $\begin{array}{c}\text { Mean } \\
\text { squares }\end{array}$ & $\begin{array}{r}\text { TSS } \\
(\%)\end{array}$ & $\begin{array}{r}\text { F-value } \\
\hline \text { Environment }\end{array}$ \\
Rep (Environment) & 5 & 2476 & 495.36 & 29 & $81.69^{* * * *}$ \\
Clone & 9 & 52 & 10.49 & 1 & $1.73^{\text {Ns }}$ \\
Env. $\times$ Clone & 45 & 4877 & 541.88 & 56 & $89.36^{* * *}$ \\
Error & 61 & 868 & 19.28 & 10 & $3.18^{* * * *}$ \\
Total & 118 & 321 & 6.06 & 4 & \\
Ns, ***** Nonsignificant or significant at $P=0.001$, respectively. & & &
\end{tabular}

\section{Results and Discussion}

Germplasm screening. An initial analysis of variance revealed a highly significant genotype effect for ascorbic acid concentration among the 75 clones, a highly significant environment effect among the six location/years, and a highly significant $\mathrm{G} \times \mathrm{E}$ interaction (Table 1). Among environments, the highest average ascorbic acid concentration was from Oregon in $2000(26.7 \mathrm{mg} / 100 \mathrm{~g})$, followed by Idaho in 2000 (24.6), Idaho in 1999 (20.1), Washington in 2000 (19.8), Oregon in 1999 (17.0), and Washington in 1999 (15.0).

When averaged across all environments, a wide range of ascorbic acid concentrations was found among clones (Table 2). The highest concentration was expressed by ND4027-4 (29.8 mg/100 g), followed by 'Ranger Russet' (29.4), 'Yukon Gold' (29.3), 'Russet Nugget' (28.7), and one of the high concentration control clones A85331-16(28.6). The lowest clone was A8792-11, one of the low concentration control clones, with an average of $11.5 \mathrm{mg} / 100$ g. Other clones with low ascorbic acid concentrations were WH10469 (13.0), A79141-3 (low

Table 5. Eigenvalues and associated variance proportions for ascorbic acid concentration of 10 potato clones grown in Idaho, Oregon, and Washington during 1999 and 2000.

\begin{tabular}{lccc}
\hline Principal & & \multicolumn{2}{c}{ Variance proportion } \\
\cline { 3 - 4 } component & Eigenvalue & Component & Cumulative \\
\hline 1 & 248.2 & 55.7 & 55.7 \\
2 & 112.6 & 25.2 & 80.9 \\
3 & 54.8 & 12.3 & 93.2 \\
4 & 20.1 & 4.5 & 97.7 \\
5 & 10.2 & 2.3 & 100.0 \\
6 & 0.0 & 0.0 & 100.0 \\
7 & 0.0 & 0.0 & 100.0 \\
\hline
\end{tabular}

With the exception of clones from Texas and Wisconsin Germplasm Enhancement (WIG), the breeding program averages for ascorbic acid concentration, inclusive of all clones within each program, were similar and ranged from 19.7 to 22.8 (Table 3 ). The high Texas average (26.5) was the result of contributing only two clones, both high in ascorbic acid content. The concentration for clones within each of the other eleven breeding programs ranged from relatively high levels of ascorbic acid to relatively low. The similarity of ascorbic acid concentration of breeding clones from one program to another is not surprising because public breeders have not systematically selected for higher levels. However, it appears that every program has parental germplasm that may be useful for improving ascorbic acid concentration.

The WIG clones represent a unique grouping among those evaluated. They consist of hybrids or progeny of hybrids of Solanum tuberosum ssp. tuberosum crossed with a variety of wild species, including Solanum tuberosum ssp. andigena, S. raphanifolium, S. sucrense, $S$. acaule, S. albicans, S. gourlayi, S. brevidens, S. chacoense, S. boliviense, S. tarijense, and $S$. phureja. Fourteen of these hybrid-derived clones were evaluated-a higher number than from any other program. A wide range of species-related materials were included with intent to determine whether any of these wild species have potential to contribute genes for high ascorbic acid to the cultivated potato germplasm base. As a group, these clones were lower in ascorbic acid than their domestic counterparts, with a breeding program average of $17.2 \mathrm{mg} / 100 \mathrm{~g}$. Ten of the 14 clones were below the median of the 75 clones evaluated, and only one (WH1327) was in the top onethird. Although this group of species-derived germplasm is small, these results suggest that genes for high ascorbic acid concentration are not common among the related wild species used to create these hybrids. nearly identical, suggesting a distribution that is not skewed. expressing control at 13.3), S438 (13.7), and WH10470 (13.9). Seventy-one percent of the $\mathrm{mg} / 100 \mathrm{~g}$ and the grand mean was $20.5 \mathrm{mg} / 100$ g. The difference in concentration between the fold. Named and released cultivars, whether or not they are common in commerce, were evenly distributed throughout the full range. The expression of ascorbic acid concentration among clones appeared to be fairly continuous

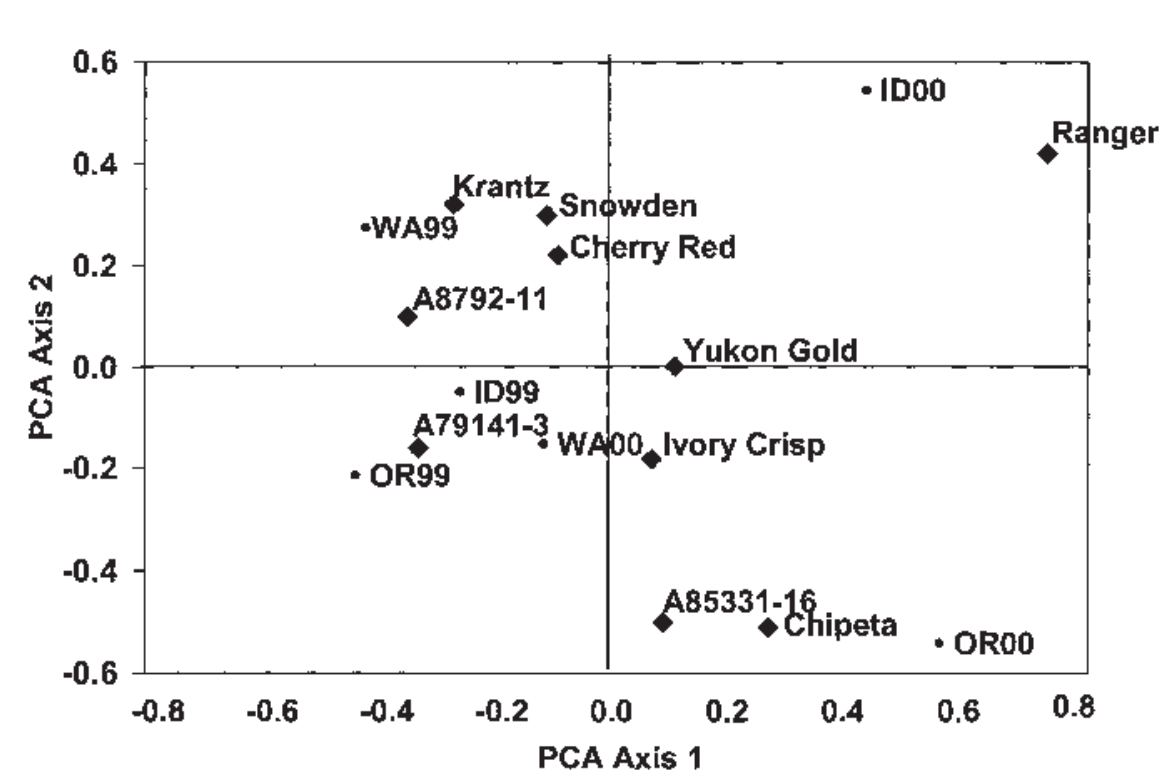

Fig. 1. Biplot of principal components analysis (PCA) axis 2 vs. axis 1 for the tuber ascorbic acid concentration of 10 selected potato clones grown in Idaho, Oregon, and Washington in 1999 and 2000. 
Screening provided evidence for genetic variability for ascorbic acid concentration among North American clones. Theoretically, this should provide the potential to intercross superior parents, select appropriate new gene combinations, and hopefully identify progeny populations with transgressive individuals.

$G \times$ Eanalysis. The contribution to variance for genotype, environment, and the $\mathrm{G} \times$ Einteraction within the subset of 10 clones is found in Table 4. The largest contributor to variance in the ANOVA model was genotype with $56 \%$ of the total sums of squares. This was twice as high as the contribution of environment, with $29 \%$. There was also a significant $\mathrm{G} \times \mathrm{E}$ interaction, although the amount of variation attributed to the interaction was only $10 \%$ of the total. This variance structure provides some critical insights into possible breeding behavior of the ascorbic acid trait. Because the largest proportion of the variation is due to genotype, heritability of this trait is probably high and good breeding progress can be expected. This was confirmed by a computation of broad sense heritability, based on the ANOVA. For this subset of 10 clones the heritability was 0.92 . This estimate of heritability is likely inflated by the inclusion of high and low concentration clones in the subset. For the entire group of 75 clones, the broad sense heritability was 0.71 .

The low contribution of the $\mathrm{G} \times \mathrm{E}$ interaction also lends itself to a conclusion that selection within an environment will probably be effective. But, the fairly high contribution of environment indicates that multiple evaluations over different environments will be needed to accurately quantify ascorbic acid.

Using the AMMI model, the $\mathrm{G} \times \mathrm{E}$ interaction was decomposed into five components (Table 5). The first two components accounted for $81 \%$ of the variability in the model, and therefore, only these two were retained. AMMI biplots are shown in Figs. 1 and 2. In Fig. 1, PCA axis 1 is plotted against PCA axis 2, for clones and environments. Clones and environments that have small interactions will appear close to the center of the axes. A79141-3, 'Yukon Gold', and 'Ivory Crisp', for example, had small interaction effects, while 'Ranger Russet' showed the strongest interaction effect of all clones included in the analysis.

The direction of each point from the axes' center provides important information about the nature of the interaction. When a clone and environment are located on opposite sides of the center, such as with 'Ranger Russet' and OR99, it indicates their contributions are opposing to the interaction. In other words, they are negatively correlated. In contrast, 'Krantz', 'Snowden', 'Cherry Red', and A8792-11 are in the same direction as WA99, indicating a positive contribution to the interaction and that these clones should perform well in that environment. The trial locations, as a component of the environments, were not consistent with respect to their direction from the center of the axes.

Fig. 2 depicts PCA axis 1 plotted against average ascorbic acid concentration for all clones and environments. This plot demonstrates that both clones and environments contributed to the variability in the model. In this plot, clones and environments that appear close to the horizontal line, where PCA axis 1 is 0 , contribute less to the interaction and are considered more stable. 'Ranger Russet' again shows a distinct lack of stability, and 'Yukon Gold' and 'Ivory Crisp' demonstrate stability. The locations OR99, WA99, ID00, and OR00 show high contributions to the interaction indicating considerable environmental variation. This suggests that wide environmental variability, and differential response of cultivars, should be anticipated during the process of screening progeny and breeding for elevated levels of ascorbic acid.

Groupings above or below the center line can reveal underlying reasons for the variance structure. In this case, there was no strong pattern with respect to locations, indicating that none of the evaluation sites consistently contribute more to the variability than any other. However, there was a strong pattern with respect to years. The 1999 trials were all grouped below the axis and all but the Washington site in 2000 (which was nearly on the axis) was grouped above the axis. This suggests that year contributes heavily to the $\mathrm{G} \times \mathrm{E}$ interaction and that evaluation across years may be more important for quantifying ascorbic acid than evaluation across locations.

There was a strong agreement between the AMMI biplots and the results of the distribution of Tai's stability statistics (Fig. 3). For this type of plot, the clones between the two vertical lines and within the parabolic curve $(\alpha=0)$ are considered to be relatively stable. 'Ranger Russet' and A8792-11 showed strong tendencies for instability, lying outside of both bounds.

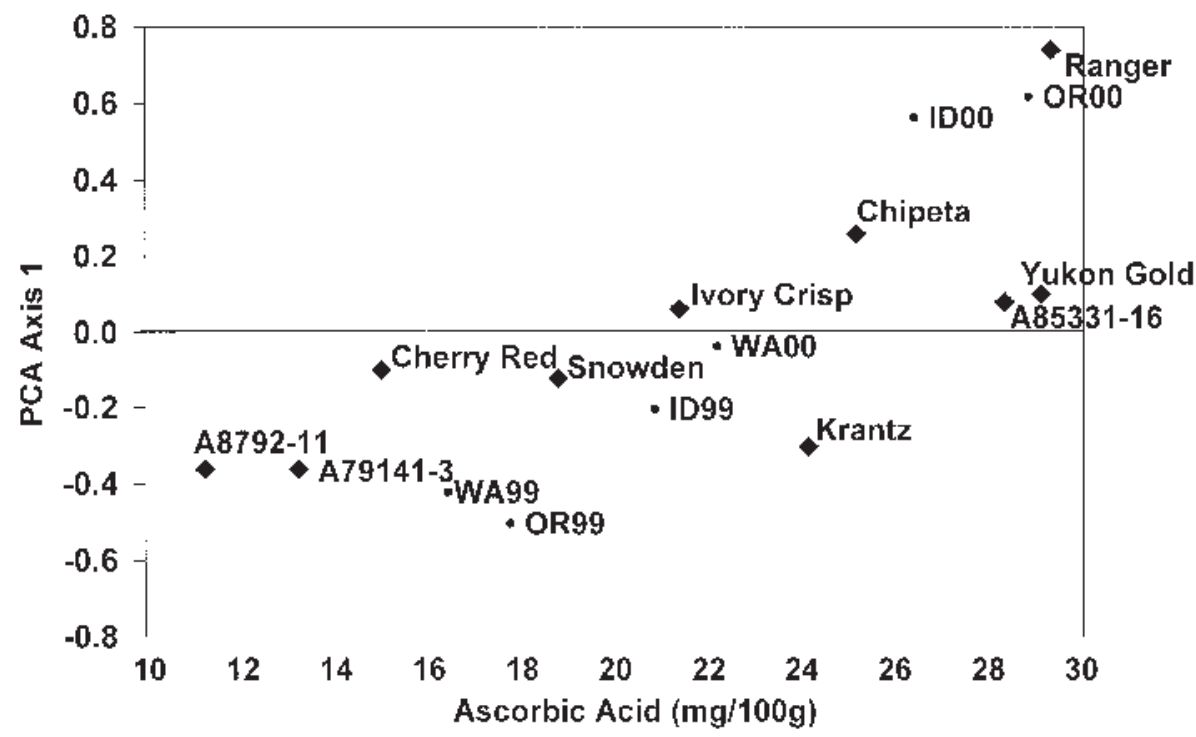

Fig. 2. Biplot of principal component analysis (PCA) axis 1 vs. mean ascorbic acid concentration in tubers of 10 selected potato clones grown in Idaho, Oregon, and Washington in 1999 and 2000.

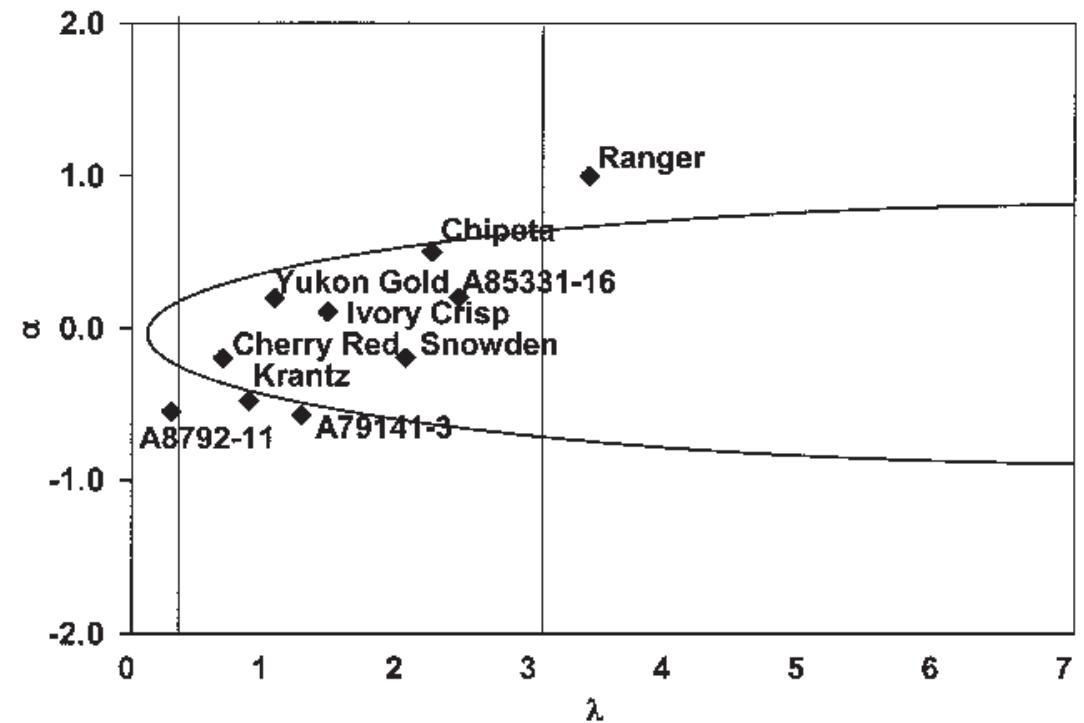

Fig. 3. Distribution of Tai's stability statistics for tuber ascorbic acid concentration of 10 selected potato clones grown in Idaho, Oregon, and Washington in 1999 and 2000. The hyperbola represents a 95\% confidence interval for $\lambda=0$; the vertical lines are $95 \%$ confidence intervals for $\lambda=1$. 
'Krantz', 'Chipeta', and A79141-3 were marginally unstable. 'Yukon Gold', A85331-16, 'Ivory Crisp', 'Cherry Red', 'Snowden', and 'Krantz' showed the best overall relative stability. Biological or morphological differences among the clones that could help explain the basis for stability could not be identified. It did not appear to be related to stress tolerance, maturity class, vine size, or any other obvious plant characteristic (data not presented).

The AMMI analysis demonstrates that these clones differ, not only for ascorbic acid concentration, but also for stability of expression across environments. If a consistently high level of ascorbic acid is to be achieved, both level and stability of expression are important considerations.

From the results of this study, several conclusions concerning the breeding behavior of ascorbic acid can be made: 1 ) there is adequate variability within North American germplasm to expect the presence of suitable genes to breed for higher ascorbic acid content in potato tubers; 2) North American potato germplasm expresses diversity for stability of expression for ascorbic acid and progeny families derived from this germplasm is likely to do the same; 3 ) given a high genotype variance, combined with a low $\mathrm{G} \times \mathrm{E}$ interaction and high broad sense heritability, rapid breeding progress can be expected if suitable parents are used; 4) selection within a single location should provide adequate breeding progress; and 5) AMMI analysis suggests that years may be more important than locations in explaining variability and multi-year evaluations are important to properly quantify ascorbic acid.

\section{Literature Cited}

AOAC. 1984. Official methods of analysis, p. 845-846. Assoc. Offic. Anal. Chemists, Arlington, Va.

Artz, W.E., C.A. Pettibone, J. Augustin, and B.G. Swanson. 1983. Vitamin C retention of potato fries blanched in water. J. Food Sci. 48: 272-273.

Augustin, J., B.G. Swanson, C. Teitzel, S.R. Johnson, S.F.Pometto, W.E. Artz, C.P. Huang, and C. Schomaker. 1979a. Changes in nutrient composition during commercial processing of frozen potato products. J. Food Sci. 44:807-809.

Augustin, J., R.B. Toma, R.H. True, R.L. Shaw, C. Teitzel, S.R. Johnson, and P. Orr. 1979b. Composition of raw and cooked potato peel and flesh; proximate and vitamin composition. J. Food Sci. 44:805-806.

Augustin, J., S.R. Johnson, C. Teitzel, R.B. Toma, R.L. Shaw, R.H. True, J.M. Hogan, and R.M Deutsch. 1978. Vitamin composition of freshly harvested and stored potatoes. J. Food Sci. 43: 1566-1574.

Bradu, D. and K.R. Gabriel. 1978. The biplot as a diagnostic tool for models of two-way tables. Technometrics 20:47-68.

Gabriel, K.R. 1971. The biplot graphic display of matrices with application to principal component analysis. Bikometrika 58:453-467.

Kemp, P. and T.C. Kemp. 1982. The ascorbic acid content of thirteen varieties of potato. Proc. Nutr. Soc. 41:6A.

Mullin, W.J., P.Y. Jui, L. Nadeau, and T.G. Smyvl.
1991. The vitamin C content of seven cultivars of potatoes grown across Canada. Can. Inst. Food Sci. Technol. J. 24:169-171.

National Potato Council. 2001. Potato statistical yearbook. Greenwood Village, Colo.

Pennington, J.A.T. and V.L. Wilkening. 1997. Final regulations for the nutrition labeling of raw fruits, vegetables, and fish. J. Amer. Dietetic Assoc. 97:1299-1305.

Shafii, B. and W.J. Price. 1998. Analysis of genotypeby-environment interaction using additive main effects and multiplicative interaction model and stability estimates. J. Agr. Biol. and Env. Stat. 3:335-345.

Storey, R.M.J. and H.V. Davies. 1992. Tuber quality. p. 507-568. In P.M. Harris (ed.). The potato crop: The scientific basis for improvement. Chapman \& Hall, London.

Sumner, J.L., S.L. Eu, and A.S. Dhillon. 1983. Ascorbic acid retention in foods. J. Food Nutr. 40:43-47.

Tai, G.C.C. 1971. Genotype stability analysis and its application to potato regional trials. Crop Sci. 11:184-190.

Wang, X.Y., M.G. Kozempel, K.B. Hicks, and P.A Seib. 1992. Vitamin C stability during preparation and storage of potato flakes and reconstituted mashed potatoes. J. Food Sci. 57:1136-1139.

Wills, R.B.H. 1987. Composition of Australian fresh fruit and vegetables. Food Tech. Austr. 39:523-526.

Workman, M. and D.G. Holm. 1984. Potato clone variation in blackspot and soft rot susceptibility, redox potential, ascorbic acid, dry matter, and potassium. Amer. Potato J. 61:723-733.

Zobel, R.W., M.J. Wright, and H.G. Gauch. 1988. Statistical analysis of a yield trial. Agron. J. 80: 388-393. 